\section{Perianeurysmal edema in giant intracranial aneurysms in relation to aneurysm location, size, and partial thrombosis}

TO THE EDITOR: We write to report an error in our article "Perianeurysmal edema in giant intracranial aneurysms in relation to aneurysm location, size, and partial thrombosis" ( $J$ Neurosurg [epub ahead of print April 17, 2015. DOI: $10.3171 / 2014.10 . J N S 141560])$. In the original version of Fig. 3, the plus (+) and minus (-) symbols on the PAE line were reversed. The corrected version of Fig. 3 is shown to the right. The figure has been corrected online as of May 29, 2015.

Julius Dengler, MD Charité-Universitaetsmedizin Berlin, Berlin, Germany

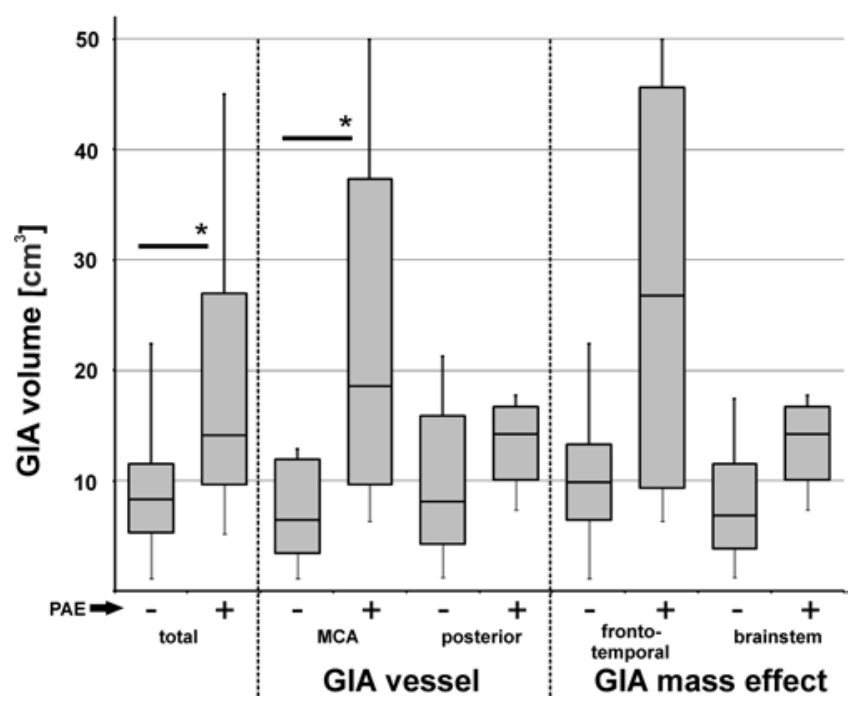

FIG. 3. Box plot of the volumes of GIAs with (+) and without (-) PAE. *p $<0.05$.

CORRESPONDING ARTICLE See pp 446-452.

INCLUDE WHEN CITING

Published online May 29, 2015; DOI: 10.3171/2015.5.JNS141560a.

CAANS, 2015 